\title{
BODEGÓN CALIFORNIANO
}

\author{
Julio Ramos \\ Berkeley University
}

\begin{abstract}
RESUMO
Uma reflexão sobre o potencial de um pensamento pósestatista a partir da análise de um pequeno mural de Diego Rivera em um dormitório da Universidade de Califórnia em Berkeley. Começaremos com um comentário sobre o "Still Life or the Blossoming Almond Trees" (1931), que nos levará ao tema da "segunda língua materna" em um poema de Rosario Castellanos, "Silencio cerca de una piedra antigua" (De: El rescate del mundo).
\end{abstract}

\section{PALAVRAS - CHAVE \\ Estudos culturais. Muralismo. Poesía. \\ Romance hispano-americano.}

\begin{abstract}
Comencé a reflexionar sobre el tema de las frutas y de la lengua hace algún tiempo en Puerto Rico, camino a la plaza del mercado de Río Piedras, donde el calor ha convertido la discusión sobre el tiempo de la espera y la duración en uno de los tópicos más recurrentes de la filosofía vernácula. En Río Piedras admiré la piña de Nick Quijano ("Apiñada") en la portada de un memorable volumen de ensayos titulado Polifonía salvaje. "Apiñada", un brillante óleo de Quijano fechado en 1992, es la hipérbole de una fruta casi redonda, inflada como un globo "apiñado" o demasiado lleno. Los colores del cuadro están intensificados por el dinamismo interno de la fruta en el frágil instante de maduración, cuando la áspera superficie de la piña se ablanda y hiede, al punto de estallar en néctar antes de podrirse.
\end{abstract}

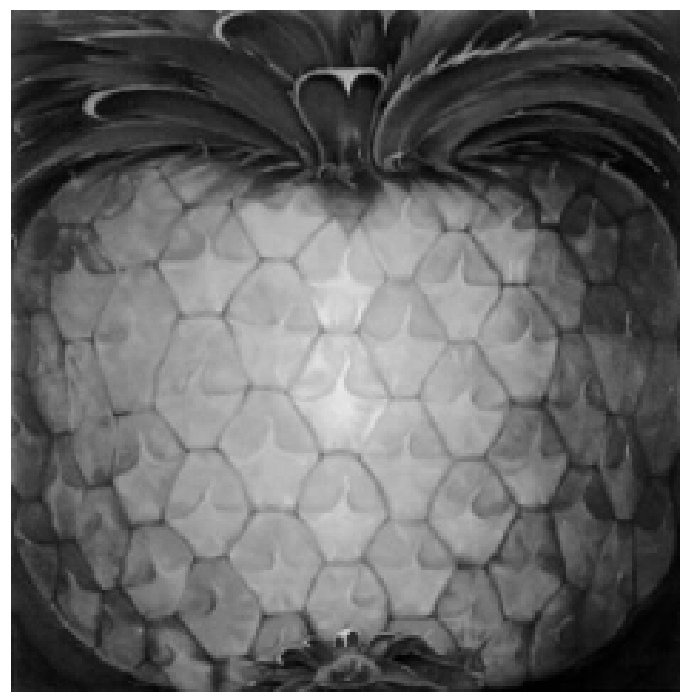

Nick Quijano, 1992. 
Esta piña, como las guanábanas o las papayas del pintor cubano Ramón Alejandro (ver "El instante perpetuo"), registran lo que la "Oda a la piña" del habanero Manuel de Zequeira y Arango aún no podía articular en su ilustrado poema:

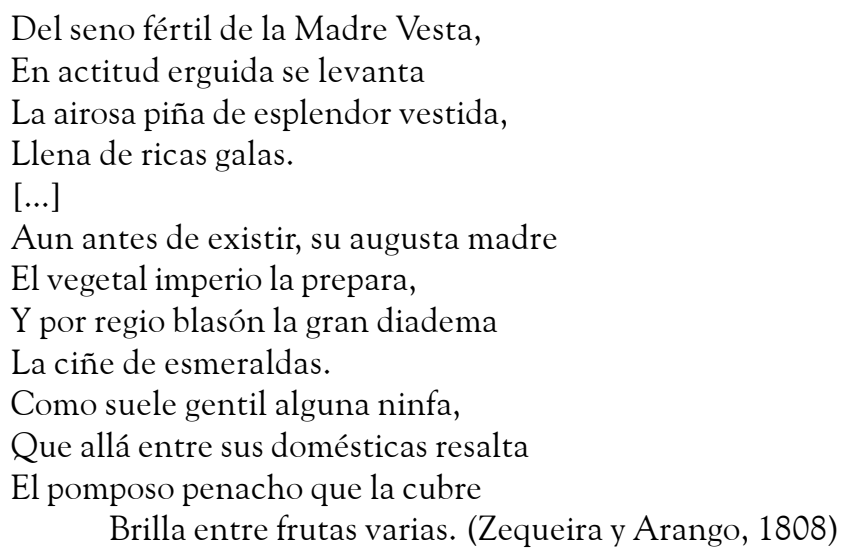

El tiempo de la piña es la promesa abstracta de su valor futuro. Cierto es que -a contrapelo de los afeites figurativos, Zequeira y Arango, uno de los fundadores de la ilustrada Sociedad Patriótica de Amigos del País- sabía bien que no hay metáfora ni cortesana ni pastoril capaz de menguar los rigores del calor y el desgaste tropical. El calor produce el otro rostro de la exhuberancia tropical: el aplatanamiento y el rápido consumo de la vida. Pareciera que por esa misma razón Andrés Bello tiende a celebrar la cáscara de otras frutas, la almendra, caña, el maíz, el café, o si no, cultivo rápido de las blandas, como la uva. La duración entonces no es sólo un problema filosófico o estético, ligado a lo que Bello llama, en su clásica "Silva a la Agricultura de la Zona Tórrida", el deseo de prolongar el "duradero gusto", sino también un respuesta a la necesidad de asegurar una prolongada circulación del fructífero goce -en tanto bien comercial - tan celebrado por el discurso poético como por las primicias de la racionalización agrícola en los árboles del tropicalismo.

Zequeira y Arango, reconocido habitualmente como uno de los "fundadores" de la poesía nacional cubana, disimula el aroma de la piña:

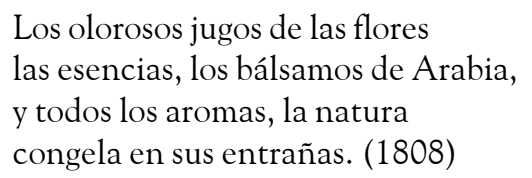

¿Qué será lo que la tropical natura congela en sus entrañas? Cuando William Carlos Williams "escucha” (y transcribe) en Rutherford, bajo la nieve de New Jersey, su lengua materna -es decir, el español puertorriqueño de su madre Helena Hoheb Monsantos, emigrada a Brooklyn de la Isla hacia los 1880- escribe un bello texto tropical: "A Memory of Tropical Fruit", donde las frutas, como en la poesía de Palés Matos, cromatizan el inconsciente racializado de su madre mulata. Williams, primer traductor al inglés de Palés, citaba el nombre de las frutas -mango, níspero, caimito, quenepas- en la lengua materna, como aludiendo a un sabor lejano en cada palabra inscrita del español citado. En cambio, Víctor Hernández Cruz -otro gran lector de Palés Matos- transplanta el trópico al Norte. Su ofrenda de frutas insiste en la jocunda epifanía de una clave (en 
el sentido musical) fantasmática - un ritmo- que abre caminos y asegura el paso en la huella acústica de los diaspóricos rumbos en las "Tropicalizations" en Manhattan o en la distante California. ¿Distante de qué? Ciertamente no muy distante del lugar donde crece la palma. A lo largo de Scenic Avenue abundan de palmas. "Aquî" crece la palma. La palma escrita. Se escribe "aquí:" no hay otro lugar para la escritura.

Los pastiches tropicalistas de los pintores Nick Quijano y Ramón Alejandro nos recuerdan que las entrañas del trópico son una máquina de combustión interna. Distantes herederos de Turner, Quijano y Alejandro exploran la combustión, no ya como un desplazamiento de la llama de los motores de la revolución industrial (ver la intrigante interpretación de Michel Serres sobre Turner) sino como un dinamismo desatado en la aparente "stasis" de la propia materia orgánica. Pero ese exceso de energía, claro, es ambivalente. Crea y desgasta la vida: hasta la mejor de las frutas, si no se come o se cocina a tiempo, se pasa. Digamos, recordando las discusiones de Walter Benjamin sobre la alegoría barroca, que las frutas de Quijano y de Alejandro apuntan al devenir del tiempo en la entraña misma de la naturaleza, y por el reverso, que estas pinturas del exceso caribeño inscriben el devenir histórico como un paisaje natural al borde de la descomposición. Las pinturas de Quijano y de Alejandro inspiran los fragmentos que siguen de un tentativo esbozo para historia ecológica de la lengua.

Volví a retomar con mayor precisión el tema hace un año y medio en Río de Janeiro, tras escuchar sobre una instalación que proyectaba la artista brasileña, Laura Vinci, en una galería de São Paulo. No pude viajar el año pasado a ver la instalación titulada "Ainda Viva", aunque sí pensé desde la lejanía californiana -donde también puede hacer mucho calor- sobre el tema del desgaste y la multiplicidad de temporalidades que explora Vinci al colocar una serie de manzanas frescas -docenas de manzanas- en pleno curso de su natural descomposición, junto al aparente hermetismo del mármol y el granito: diversos grados de porosidad de los elementos, ritmos y condiciones variadas de la duración de los cuerpos orgánicos e inorgánicos en un espacio intervenido y acelerado por varias detonaciones de bala que dramáticamente aludirían -supongo ahoraa la fragilidad de cualquiera de aquellos ritmos, superficies o tiempos que bien pueden ser destruidos en un abrir y cerrar de ojos por el mínimo y brutal impacto de una bala: 


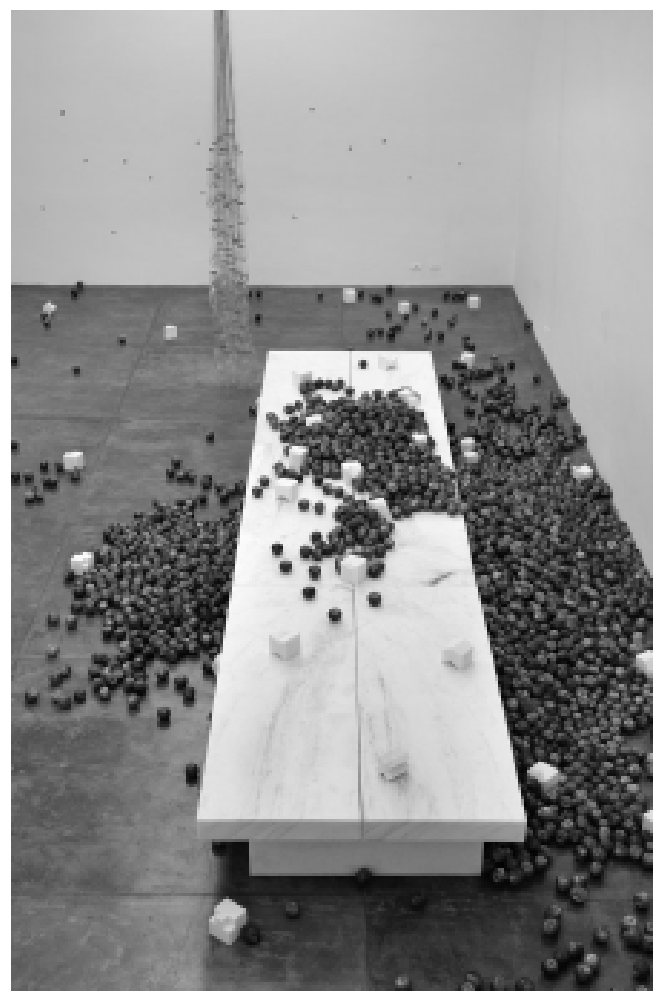

Laura Vinci, Ainda viva.

Entre los balazos, las manzanas y el mármol, cuelgan los cables de una transparencia que no conecta ni "transmite" la correspondencia entre las superficies y sus tiempos. Pero el bodegón postindustrial de Vinci, en vez de llamarse "Natureza morta", se titula "Ainda viva", que bien puede traducirse al inglés como "Still Alive," que se pronuncia casi igual que "Still Life", es decir, "Naturaleza muerta". La obra de Vinci explora el estado de la quietud que Sara V. Perryman llama el "quivering potential" (manuscrito inédito) de ciertas formas del "reposo". Una quietud, digamos, sin la jactancia de los que la hacen pública. Está ainda viva, porque para un arte materialista como el de Vinci no puede haber natureza morta, a pesar de las balas.

Decía hace un segundo que el hermetismo del mármol es sólo aparente -su voluminosa o monumental clausura- porque los que conocíamos algo de las instalaciones anteriores de Vinci sobre los ritmos desiguales de la descomposición y el desgaste sabemos que en su obra hasta el mármol se hace polvo y se alegoriza. Su obra, tan alerta a los temas del materialismo clásico, explora el fluir de las cosas incluso en lo pesado y lo inamovible.

Como el canvas con la tierrita en las botas del campesino de Van Gogh, el arte de Vinci explora la asincronía de la duración y los distintos niveles de consistencia del volumen de la materia atrapada entre el engranaje del tiempo tecnologizado: en otra de sus instalaciones, el mármol molido se acumula en un espacio industrial abandonado como un arcaico reloj de arena. Vinci separa los instrumentos de la técnica industrial de la performance laboral y así los hace profundamente extraños. Su arte investiga la multiplicidad dislocada de las fuentes sensoriales (sonido, olor, visibilidades), pero lo hace sin renovar aquel reclamo moderno de la autoridad reintegradora del arte, es 
decir, la mediación del sistema compensatorio de equivalencias, correspondencias o sustituciones que la estética moderna había intentado recomponer para el mundo industrial, secularizado, donde se han desgranado y se sometido a nuevas lógicas de circulación los restos de cualquier instancia de trascendencia, ahora incluso la más moderna de las ilusiones de trascendencia por mediación técnica. El arte postsecular de Vinci no restituye la trascendencia.

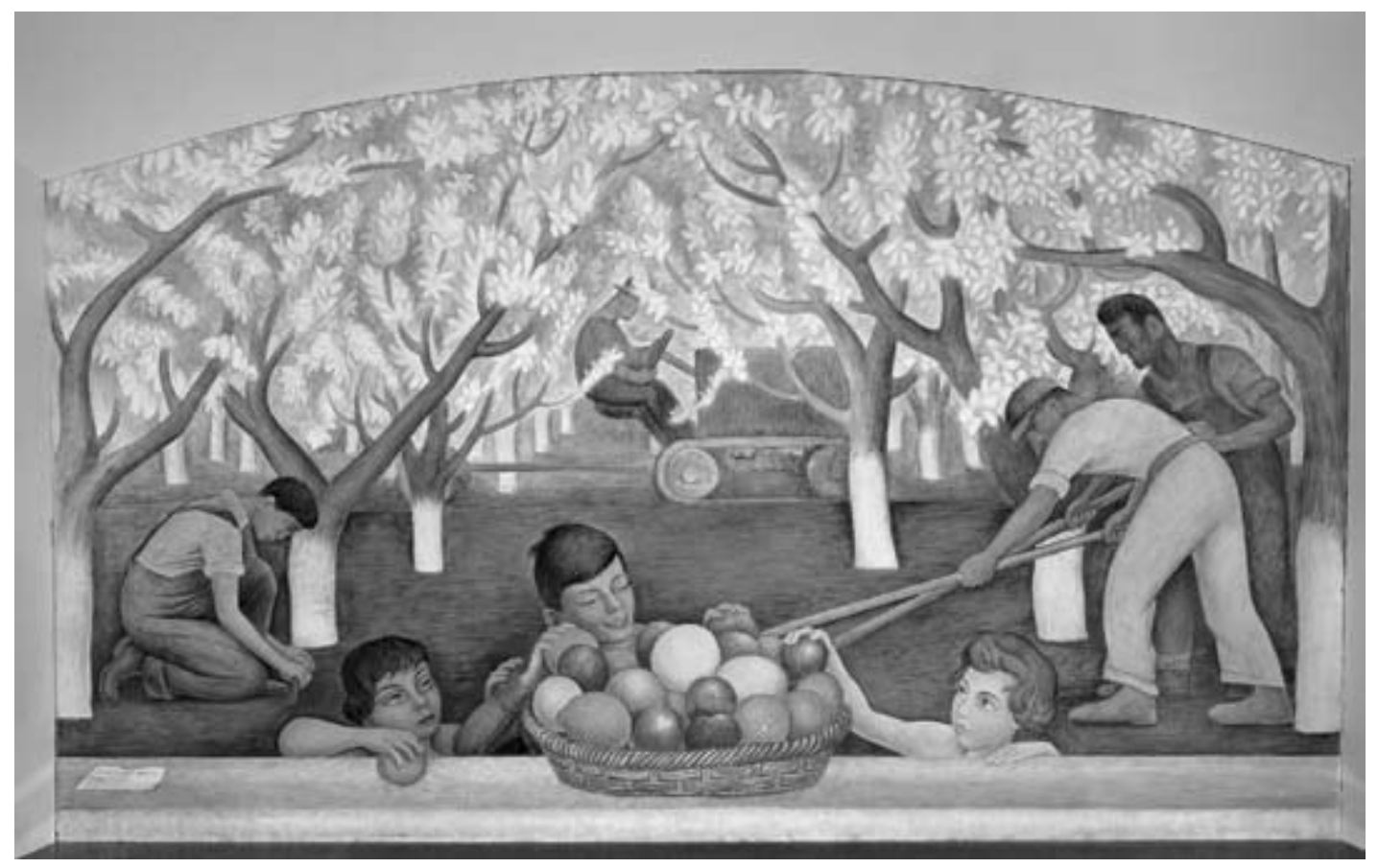

Still Life With Blossoming Almond Tree de Diego Rivera (1931)

Foto: Manuel Santiago. Stern Hall, University of California, Berkeley.

Agradecimientos al Rector y a los Regentes de la UC.

Ahora les hablo de Still Life With Blossoming Almond Trees de Diego Rivera (1931). Este bodegón cosmopolita, un pequeño fresco prácticamente desconocido del muralista mexicano, pintado en los primeros años de su primera estadía en los Estados Unidos entre 1929-35, se encuentra a la entrada de un dormitorio en el campus de la Universidad de California, Berkeley. La pintura, hecha sobre un fino empañetado de concreto, fue comisionada por una coleccionista, Rosalie Meyer Stern, durante la prolongada estadía de Rivera en California. El fresco se trasladó del sur de California a Berkeley y luego donado a la universidad para adornar el dormitorio, Stern Hall, después de su apertura en el 1942.

¿Resistirá la distancia del viaje la imagen de la ofrenda de frutas, la lengua que porto pegadita al paladar? No dudo que tampoco ella -la fruta lengua- (mucho menos el que la porta) resista el impacto del tiempo como el de balas. ¿Cuáles podrían ser hoy las condiciones de una enseñanza alerta a su necesaria ecología? ¿Será necesario que ante mi participación en este Congreso de la Lengua, por así llamarlo, se pregunten iquién es quien la porta -a la lengua; idesde dónde la trae, cuáles son sus credenciales, qué lo autoriza a hablar?; sí, ¿qué legitima al portavoz que la traslada entre puertos, no 
ya sólo entre lugares, sino entre aduanas, cruzando las instituciones que la guardan y la administran y que sin embargo erigen sus estructuras en la irreductible exterioridad de la lengua. La lengua paradójicamente es tanto el objeto de esas instituciones como la materia misma de su innombrable condición de posibilidad. Es objeto y materia del discurso mismo. ¿Desde dónde entonces hablarla?

De California la porta al que le toca evocarla. ¿Que con quién la ha andado o la ha puesto en contacto por el camino? ¿Les bastará saber que el que la habla y la acompaña ha bajado -como cualquier otro entre ustedes- hasta las extremidades del bien gramatical? ¿Cuál es después de todo el cuerpo de un "bien gramatical”? ¿Tiene extremidades el cuerpo gramatical, tan cercano históricamente del cuerpo jurídico?

Les advierto que no propongo una empresa de ex-portación de la lengua, como en aquella lógica de la sustitución de bienes que rige aún los mapas imperiales: el circuito colonial del explorador que trae, a cambio de las frutas frescas, una lengua en conserva, preservada, acaso embalsamada (la lengua del clásico que a pesar de la violencia de la instrumentalización de su lengua no cesa de hacernos reír o hasta de soñar nuevos rumbos para la lengua). ¿Que de dónde viene la lengua? La pregunta que proponemos es otra: ipor dónde y con quién anda? Preguntas, obviamente, de carácter ético y teórico que probablemente marcan el porvenir de la enseñanza del español en cualquier parte, incluso seguramente en el Brasil donde el español ha sido oficializado como una segunda lengua, requerida para la educación ciudadana.

¿No será posible pensar que la lengua se nos da aquí mismo? ¿Qué nos impediría pensarlo así? Nos lo impide, primeramente, un pensamiento que piensa la lengua del vecino o del inmigrante como una lengua extranjera. Piensen por un segundo en las implicaciones contemporáneas de la palabra “extranjero” en Francia, España o California. ¿Qué es hoy un extranjero? ¿De dónde viene la palabra? ¿Cómo afecta la globalización la mutación de sus contenidos? ¿Será suficiente pensar que la "extranjería”, como sugiere Kristeva en un libro muy útil (1991) se repliega en el inconsciente de la subjetividad? ¿Qué diría hoy la profesora de origen búlgaro sobre la proliferación de nuevos esquemas acústicos y lingüísticos africanos en París o dominicanos y mexicanos tan cerca de Columbia University? Hoy por hoy pensar al vecino (de casa) como "extranjero" representa un acto de negación u oclusión peligrosa. Digamos, parafraseando a Fanon: "Mira, mamá, un extranjero...Mira mamá, un extranjero pobre y negro. Una extranjera negra. Mamá: ¿Es una extranjera pobre o un extranjero la negra?" La hostilidad o la fobia, frecuentemente inconsciente, inscribe las posiciones del que tiene o del que no tiene acceso al documento de identidad -escrito en la lengua oficial. Esa es una de las condiciones principales del acceso a la ciudadanía (desde las gramáticas de Andrés Bello): la lengua reconocida por el estado, la lengua que recorre la economía de la actual industria de la lengua en ese millonario circuito de las sustituciones entre "metrópolis" y "periferia", que se desliza cómoda y discretamente entre las aduanas con los mapas del imperativo pedagógico que todavía hoy supone e impone la ficción de la lengua en tanto "fiel compañera del imperio" y su corolario moderno: los territorios y los estados nacionales.

La lengua es materia tan sensible como porosa y regenerativa. Si me permiten, quisiera sugerir ya que las labores de un cosmopolitismo contrahegemónico, alerta a las 
condiciones contemporáneas de la globalización, ubica la cuestión de la multiplicidad lingüística en el corazón mismo de una reflexión sobre el derecho y la reelaboración crítica de los viejos moldes de la ciudadanía, pero no a partir de la interpelación negativa y las connotaciones modernas, a veces francamente fóbicas, de la "extranjería" convocada en torno de la diplomática sobremesa de discusión kantiana. Al cosmopolitismo de la "paz perpetua" de Kant se le puede responder con la mismísima perplejidad crítica de H. Arendt ante las abstracciones de los "derechos universales del hombre" (inglés, alemán o francés; véase "La perplejidad de los derechos humanos"). ${ }^{1}$

Hoy por hoy, si la lengua no viaja de Europa se le piden documentos en cualquier parte de los Estados Unidos. Se le pide ansiosamente el documento en el banco hasta a la muy jovial y rejuvenecida mandarina, dueña ya, a pesar de la joven edad, del propio banco, o al árabe y a la belleza persa que recuerda de vez en cuando la escena primeriza de educación de los griegos bárbaros. Ni hablar entonces de la melancolía californiana de aquel lingüista de la biblioteca de Borges especializado en los estudios de un dialecto samoyedo-lituano del guaraní.

La "lengua extranjera" es el corolario diacrítico y contemporáneo de la "lengua nacional": ordena y clasifica lo que hay "fuera" en el mundo de "ellos" con el mismo vigor, ya sea bélico o diplomático, con que la instituciones del bien gramatical y de la lengua nacional ordenan y clasifican las desiguales inclusiones "dentro" del territorio nacional mismo. Así se postula y se administra el gobierno de las verdades de la ciudadanía: parcialmente como un efecto de la educación gramatical, aunque simultáneamente, por razones bastante obvias, las condensaciones y dislocaciones del capital contemporáneo obligan a crear nuevos modos de aproximación a la pluralidad lingüística, nuevos modos de pensar, digamos, la traducción entre lenguas requrida para la convivencia en las complejas sociedades contemporáneas. Esta necesidad de la democracia participatoria obliga a crear nuevas prácticas y conceptualizaciones pedagógicas capaces de encarar la tendencia a la "extranjerización" o "minorización" interna de millones de hablantes bajo los principios de una gubernabilidad cada vez más atrincherada y contenida por el monolinguismo del creciente estado de la "excepción" contemporánea.

Más de 25 millones de hispanohablantes residimos en los Estados Unidos, el 10\% de la población del país. ¿Diremos entonces que se trata de una lengua extranjera? ¿Cuál podría ser el perfil de una gramática portátil y práctica, atenta a los vaivenes de la condición postimperial de la contemporánea lengua española? Hace unos años intenté indicar cómo la aparente extemporalidad del cuadro normativo y prescriptivo, en la obra gramatical y jurídica de Andrés Bello, se encontraba profundamente ligada a la inscripción disciplinaria del cuerpo y del sujeto requerida por la temporalidad del Estado moderno. ¿Cómo repensar hoy la tarea de una gramática alternativa, no contenida por la ficción del tiempo estatal homegenizado? Me refiero a algo tan sencillo como lo siguiente: una enseñanza del español comprometida con la intensificación democrática

${ }^{1}$ ARENDT. Las perplexidades de los derechos del hombre (de Los orígenes del totalitarismo). 
y participatoria. Una gramática sin universales para el uso de maestros capaces de someter la dimensión centralizada y normativa, la ley de la lengua, al quehacer de la vida estimulada por la riqueza creativa de la escena pedagógica misma, donde de hecho se fusiona en cada momento -en las prácticas del aula- el balbuceo anticipatorio de las conversaciones, del amor o de las disputas del porvenir.

Diego Rivera pintó el mural sobre los almendros cuando el cuadro canónico de Van Gogh, Almendros en flor ya era muy conocido en el medio artístico:

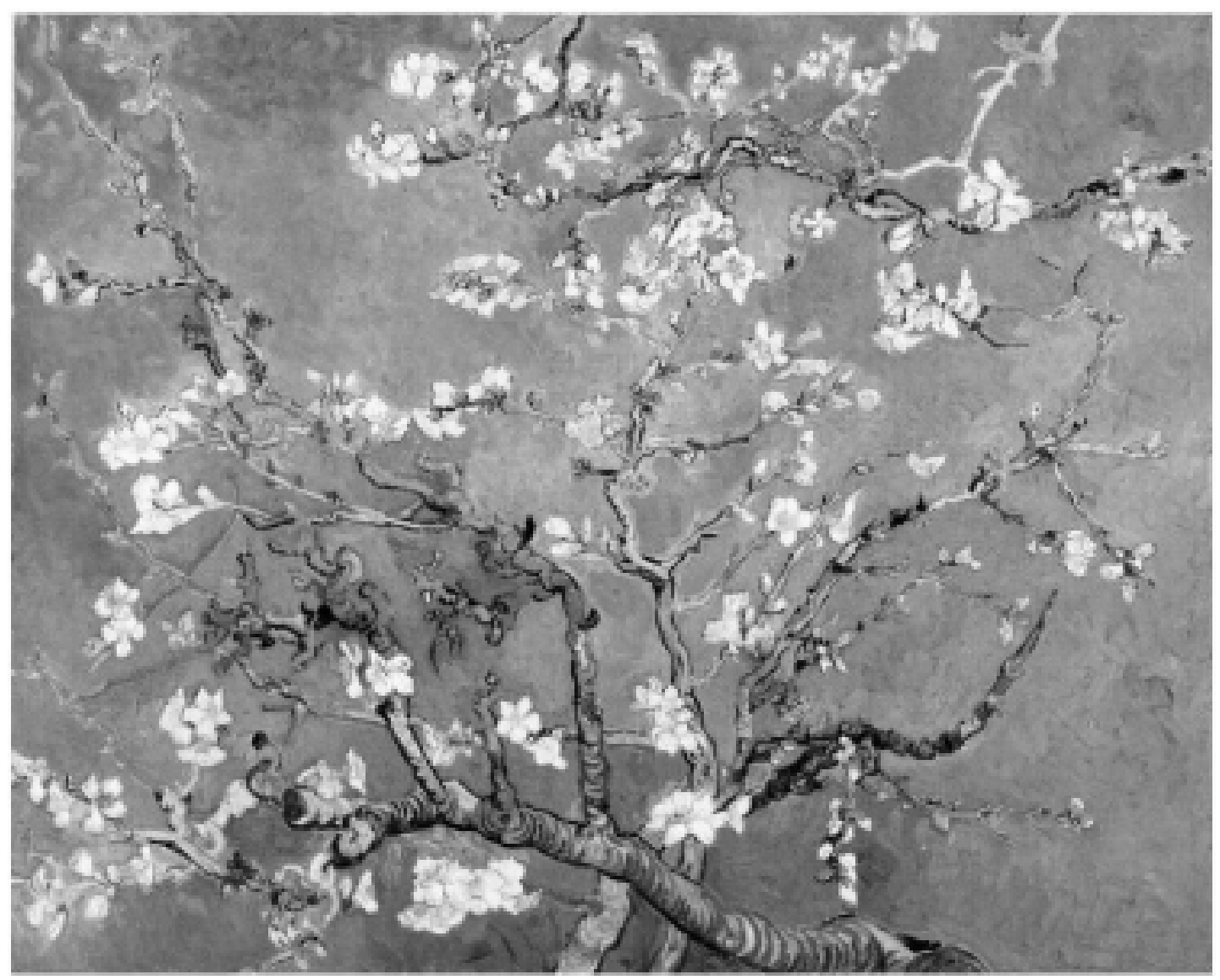

Almendro en flor, Vincent Van Gogh

Ambas obras, el canvas pintado por Van Gogh en 1890, y el fresco de Rivera pintado casi cuarenta años después, sugieren mucho sobre el proceso de la creatividad, aunque desde perspectivas muy distintas: en el cuadro del primero, un regalo para sus sobrinos, los hijos del benefactor Teo, Van Gogh identifica la creación del valor -la belleza del almendro en flor- como un efecto de génesis natural, sin aparente intervención humana. Rivera introduce dimensión pragmática o performativa de la producción - una especie de metafísica del trabajo y de la práctica que si bien registra en el cuadro el valor de condición estética del almendro, inserta la naturaleza en un circuito del cultivo tecnológico, del trabajo y la circulación. Por cierto, el materialismo abstracto del fresco no es necesariamente menos idealista que el de Van Gogh: Rivera somete la materia de la tierra y el cuerpo del trabajador ordenamiento visual muy 
idealizador de la producción: un trabajo sin desgaste ni esfuerzo visible, desentendido de los estragos del tiempo. Por eso hablo de una metafísica del trabajo. La geometría industrial de las proporciones diseña ahí la superación estética de la explotación, abstrayendo el tiempo, hipostasiando el tiempo de su condición física que sin embargo permanece como el soporte mismo del valor.

Veamos: si en el plano superior aparece el tractor, justo arriba de los tres cuerpos racializados del trabajo manual, es curiosamente en el primer plano, abajo, donde vemos el lugar de la cesta colocada entre los niños. Allí las frutas se hacen visibles, listas para el consumo. En ese punto, el del consumo (y no el de la producción), se produce el contacto entre los grupos étnicos o raciales: en el lugar del intercambio de la fruta entre la niña blanca y los dos niños de piel oscura. El contacto entre las razas se produce en ese primer plano del intercambio, donde la fruta por primera vez se hace visible en tanto objeto, signo intercambiable, y por lo tanto, cifra de valor (y belleza).

Por cierto, el circuito del intercambio no termina con el rigor abstracto, geométrico, de las proporciones en esa superficie disciplinada de la armonía en el fresco de Rivera. El circuito de la resignificación de las frutas tampoco termina con esa instancia de multiculturalismo "light" explicitada por una interpretación reciente que hace de la pintura Robert Brigneau, actual Rector de la Universidad de California en Berkeley, quien interpreta emblemáticamente la presencia del mural de Rivera en el campus como el símbolo de una universidad "comprometida" -engaged- con una misión pública, instrumentalizando de hecho el memorable pasado del activismo social de la ciudad y la militancia estudiantil de la zona de la Bahía, precisamente durante este periodo actual de despolitización universitaria y de agigantados pasos hacia la privatización de una gran universidad pública; época de ineficientes estrategias para la administración empresarial de la educación y de cancelamiento de la autonomía de las labores intelectuales y ciudadanas del claustro. La interpretación del Rector, publicada en el número de invierno del 2008 de la revista The Berkeley Promise, sobre misión social de la educación en Berkeley, se escribió durante los mismos meses en que el Congreso norteamericano debatía en Washington sobre la criminalización, la condición jurídica, médica y educativa de los 10 millones de inmigrantes indocumentados que sostienen, entre otras cosas, la economía agrícola del país, sobre todo en California, su mayor abastecedor de frutas y alimentos.

Permítanme enfatizar el punto: la culturalización y el consumo culturalizado del deseo (de contacto e intercambio) no es simplemente instancia de una instrumentalización multicultural del arte o la cultura de América Latina en una universidad del "Norte". Esa historia ya la conocemos demasiado bien. Se trata del concomitante efecto de la estetización y armonización del cuerpo y del consumo cultural y material acarreado por los mismos intelectuales del Sur, en este caso, nada menos que un indiscutido clásico de la "izquierda latinoamericanista", en esa especie de utopía industrial y agrícola, muy a tono con la propia estética modernizadora de sus paneles más clásicos para el gobierno revolucionario. La culturalización del deseo opera como la mediación entre el norte y el sur, ya sea en las disciplinas humanísticas más tradicionales, en los estudios culturales o literarios o en las complejas redes de comunicación transnacional posibilitadas por la traducción o por la enseñanza de la lengua. 
Volviendo al tema, el tiempo de las frutas y de la lengua, conjeturemos un poco ante el mural de Rivera y preguntemos: ¿cuál podría ser la palabra que se intercambia en el lugar de la reciprocidad donde la niña recibe la fruta? Unos años después de la estadía de Diego Rivera en California, Octavio Paz visitaba la ciudad de Berkeley. Paz viajó a Berkeley desde Los Angeles, donde había entrado presenciado la "orfandad" pachuca. Escribe Paz en El Laberinto de la soledad:

Recuerdo que una amiga a quien hacía notar la belleza de Berkeley, me decía: -"Sí esto es muy hermoso, pero no logro comprenderlo del todo. Aquí hasta los pájaros hablan en inglés. ¿Cómo quieres que me gusten las flores si no conozco su nombre verdadero, su nombre inglés, un nombre que se ha fundido ya a los colores y a los pétalos, un nombre que ya es la cosa misma? Si yo digo bugambilia, tú piensas en las que has visto en tu pueblo (...) Y la bugambilia forma parte de tu ser, es una parte de tu cultura, es eso que recuerdas después de haberlo olvidado. Esto es muy hermoso, pero no es mío, porque lo que dicen el ciruelo y los eucaliptos no lo dicen para mí, ni a mí me lo dicen.

El esencialismo lingüístico fundamenta el tema de la pérdida radical, la orfandad, que Paz le adjudica a los pachucos, los que perdieron su lengua, su herencia, tal como lo ha notado Silviano Santiago con tanta agudeza. La historia reciente de la globalización confirma algo muy distinto de lo que percibió Paz: Los Angeles y Nueva York se encuentran entre las ciudades de mayor número de hispano-hablantes del mundo. Hablan en los múltiples registros de una lengua doblemente extranjerizada o minorizada, tanto por el Estado, como por los marcos territoriales y eurocéntricos del hispanismo oficial que los pretende educar. Heredero del culturalismo de las nostalgias imperiales promovidas después de la guerra del 1898, el hispanismo oficial ejerce todavía hoy una influencia notable sobre el imaginario geopolítico de los estudios literarios latinoamericanos, tan marcados por el legado filológico y el pensamiento lingüístico de figuras como Pedro Henríquez Ureña, Amado Alonso, los alumnos de Raimundo o María Rosa Lida, o el mismo Alfonso Reyes, figuras canónicas de nuestro campo aludidas recientemente por el joven lingüista dominicano Juan R. Valdez en su excepcional disertación sobre el pensamiento lingüístico de Pedro Henríquez Ureña y las ideologías en torno a esa construcción imperial, tan abstracta como realmente efectiva, que llamamos la lengua hispana. Los manuales gramaticales estudiados por Rômulo Monte Alto proveen amplia evidencia de los efectos institucionales y pedagógicos que tales ideologías continúan ejerciendo entre nosotros y nuestros alumnos.

Nosotros mismos hemos descuidado la condición pragmática y el potencial político de la teoría en la enseñanza de la lengua fomentando a veces una profunda división del trabajo y una oportuna autonomía del estudio literario o "teórico" de la abundancia vital y política de la enseñanza. ¿De qué "nosotros” se habla aquí?

La fruta pasa por el paladar y por el amor de la lengua. El amor de la lengua es la locura de la filología, locura, según la consabida fórmula lacaniana, porque ofrece lo que no puede darse, lo que nunca se tuvo ni se podía tener, precisamente, un modelo estable y fundamentado de la lengua. Ese es el malestar faustiano del filólogo que explora Coppola en su última película, Youth without Youth, armada a partir de un binomio moderno: o la lengua o la vida. Hoy pedimos algo distinto: la lengua viva como condición del deseo y de la política. Ahora bien: icómo se puede recuperar de ese antiguo malamor 
filológico un joven maestro de la lengua? Conociéndo al dedillo el mal de amor de la lengua (la filología) la poesía responde:

"Silencio cerca de una piedra antigua"

Estoy aquí, sentada, con todas mis palabras

como con una cesta de fruta verde, intactas.

Los fragmentos

de mil dioses antiguos derribados

se buscan por mi sangre, se aprisionan, queriendo

recomponer su estatua.

De las bocas destruidas

quiere subir hasta mi boca un canto

un olor de resinas quemadas, algún gesto

de misteriosa roca trabajada.

Pero soy el olvido, la traición,

el caracol que no guardó del mar

ni el eco de la más pequeña ola.

Y no miro los templos sumergidos;

sólo miro los árboles que encima de las ruinas

mueven su vasta sombra, muerden con dientes ácidos

el viento cuando pasa.

Y los signos se cierran bajo mis ojos como

la flor bajo los dedos torpísimos de un ciego.

Pero yo sé: detrás

de mi cuerpo otro cuerpo se agazapa,

y alrededor de mí muchas respiraciones

cruzan furtivamente

como los animales nocturnos en la selva.

Yo sé, en algún lugar,

lo mismo

que en el desierto el cactus,

un constelado corazón de espinas,

está aguardando un hombre como el cactus la lluvia.

Pero yo no conozco más que ciertas palabras

en el idioma o lápida

bajo el que sepultaron vivo a mi antepasado.

(CASTELLANOS. El rescate del mundo, p. 108-1.090)

Este poema de Rosario Castellanos explicita el peso asociativo que portaba la fruta en el esquema visual y mudo de las artes plásticas: tropo del paladar, vecino de la lengua, se prueba y se sabe en la boca (aunque es cierto que la pintura veces nos agarra como los maestros jesuitas por la oreja). Pero si en el mural de Rivera la fruta se hace visible en tanto signo y valor solamente en el momento del intercambio, -en un armónico juego de reciprocidad infantil, intercambio de la primera palabra en otra lengua o del primer beso (con que fantaseó temerosa Miranda, la hija de Próspero, en las lecciones de lengua al joven Calibán) - en cambio, el poema de Castellanos introduce una nueva dimensión: la violencia y el olvido como condición del intercambio, es decir, del discurso mismo del amor de la lengua. Castellanos - la arrastra el apellido paterno- se ubica en el lugar de "la traición, el olvido": el lugar de la traductora. ¿No arma el amor de la lengua un estrepitoso drama de la traición? ¿No es ése precisamente el punto de cierre de Balún Canán, cuando la niña piensa que su deseo ha sido causa de la muerte de su hermano menor, Mario, el heredero del legado y del archivo paterno? ¿Qué se hace 
después de la muerte o desaparición del otro? ¿Escribir para expiar la culpa? La traición y la culpa se encuentran entre los tópicos más silenciados del latinoamericanismo, particularmente en su zona de la mediación letrada, como en El zorro de arriba y el zorro de abajo de Arguedas, donde la culpa lleva a la impotencia y acaso al agotamiento final de la vida misma.

Digamos, para evitar el drama, que en el caso de Castellanos el primer olvido recuerda muy bien las letras del nombre propio del clásico del latinoamericanismo en la poesía: Pablo Neruda. Escribe Castellanos:

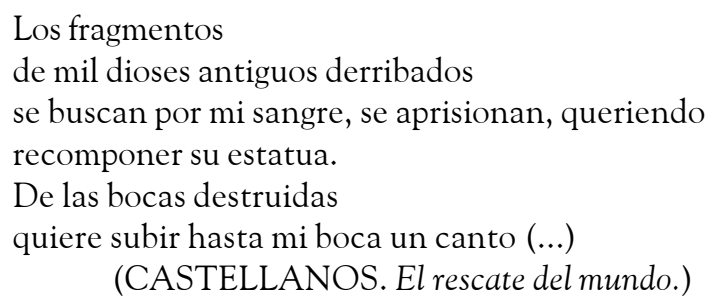

No puedo determe aquí en el análisis puntual de cuatro aspectos de la elaboración metafórica (latinoamericanista) en ambos poemas: primero, el vocabulario fúnebre, segundo, la referencia a la voz y al canto fantasmático, tercero, los estratos geológicos y arquelógicos, y cuarto, el lugar mediador del sujeto poético ubicado entre la fragmentación y la recomposición del pasado, el olvido y la memoria. Intenté iniciar la genealogía de algunas de estas posiciones en el libro cuya traducción acaban generosamente de publicar en la UFMG: Desencontros da modernidade na America Latina. Se trata evidentemente de dos poemas muy divergentes ante los parámetros de la autoridad latinoamericanista. El poema de Castellanos es una elaboración intensa y una lectura performativa de Pablo Neruda. No dudo, por cierto, que el hecho de que sea una mujer quien reescribe y resignifica las posiciones de la autoridad latinoamericanista tenga muchísimo que ver con la intensificación crítica del clásico. Por años Silvia Molloy ha insistido que los discursos clásicos del latinoamericanismo (Martí, Rodó etc.) inscriben deseos y posiciones de habla diferenciadas por el género y la sexualidad de los sujetos, más acá de las frecuentemente abstractas impugnaciones anticoloniales de los clásicos.

Neruda había publicado su Canto general precisamente en México en 1950: el libro ejemplar y de mayor influencia en la poesía social o comprometida latinoamericana hasta bien entrados los años 60. Si en "Alturas de Macchu Micchu" (1948) el sujeto emprende un viaje épico hacia la altura del arche entre las ruinas imperiales, la voz de Castellanos se ubica en un lugar muy preciso de enunciación, el "aquî" del cuerpo de la mujer "sentada". Así se abre el primero paso la posibilidad de una pragmática de la lengua que apunta a las condiciones de su condición física. Ese lugar, sin embargo, es el lugar de un silencio muy íntimo, portador apenas de una anticipación: la palabra no es aún inscripción, forma, ni categoría. Recordemos el final del poema de Neruda: "hablad por mis palabras y mi sangre”. En cambio, en el poema de Castellanos el verso donde "quiere subir hasta mi boca un canto" deviene pugna, balbuceo, a la vez que desarma decididamente, con ese mismo balbuceo, el reclamo de totalización del clásico. 
¿Diremos que se trata entonces de un texto indigenista? Depende lo que se quiera decir por "indigenismo". Si por indigenismo entendemos, con Rama, Cornejo Polar, Rowe, Liennhard y otros, el drama y las instituciones de la "traducción" y de la mediación del mestizaje o de la transculturación letrada, este poema de Castellanos abre otro rumbo y registra el límite del indigenismo institucional en México: las operaciones retóricas que fundamentan la mediación. Con Los ríos profundos de Arguedas, este poema, que bien puede leerse junto a la novela Balún Canán, registra el cierre de uno de los grandes "relatos" legitimadores del latinoamericanismo: la ficción de representatividad de la voz subalterna, no sólo en la literatura indigenista y el americanismo desde Martí, Nicolás Guillén o Neruda, sino también de las retóricas políticas del populismo testimonialista.

Castellanos lleva esa ficción dominante del latinoamericanismo al límite y a su punto ciego: el límite hispánico del latinoamericanismo. "Hablad por mis palabras y mi sangre" es un imperativo de Neruda en una lengua a la cual no responde el destinatario de la interpelación. Castellanos ubica la voz en el reconocimiento (en su caso y en el caso de Neruda, un reconocimiento fúnebre) de que la lengua ha sido labrada como una piedra por el olvido de las voces, huellas de los sujetos que la transitan.

¿No es ese otro entre los amores de la lengua: la fuerza que impulsa la entonación del poema de Castellanos, que en la "oscuridad" postula -sin titubeos, con decisión- la opción de otro saber fundado no ya de la respresentación sino en las éticas de la participación y la justicia? Los poetas cuentan entre los maestros capaces aún de escuchar la anticipación de las lenguas futuras.

\section{A4}

\section{RESU MEN}

Una reflexión sobre el potencial de un pensamiento posestatista a partir del análisis de un pequeño mural de Diego Rivera en un dormitorio de la Universidad de California en Berkeley. Comenzaremos con un comentario sobre el Still Life or the Blossoming Almond Trees (1931), que nos llevará al tema de la "segunda lengua materna" en un poema de Rosario Castellanos, "Silencio cerca de una piedra antigua" (De: El rescate del mundo).

\section{PALABRAS - CLAVE}

Estudios culturales. Muralismo. Poesía hispanoamericana. 


\section{B I B LIOGRAFÍ A}

ARENDT, Hanna. Las perplejidades de los derechos del hombre. In: . Los orígenes del totalitarismo; e incluido en la selección editada por BAEHR, P. The Portable Hannah Arendt. New York: Penguin Books, 2000.

BENJAMIN, Walter. El origen del drama barroco alemán. Trad. José Muñoz Millanes. Madrid: Taurus, 1990.

CASTELLANOS, Rosario. El rescate del mundo. Tuxtla Gutiérrez, Gobierno del Estado de Chiapas: Departamento de Prensa y Turismo, 1952.

KRISTEVA, Julia. Extranjeros para nosotros mismos. Trad. Xavier Gispert. Barcelona: Ed. Plaza \& Janés, 1991.

PAZ, Octavio. El laberinto de la soledad. 21. ed. México: Fondo de Cultura Económica, 1992. 